\title{
Social Responsibility in Supply Chain. The Coop Italia Case
}

\author{
Vincenzo Tassinari*
}

\begin{abstract}
An objective weak point in the globalization process is the traditional system of States: once we had the scheme 'one State-one market', today it is 'more Statesone market'.

Today, large-scale retailers, and industrial companies in general, cannot ignore the impacts generated by their activity, whether direct or indirect. The 'new way of thinking' they can adopt is an internal change that must always respond to market and business logics, but that can and must interact with the other actors of society for the most complex processes.

In this context, Coop stands as a point of reference for Italy 'Country system', both for the historical role of service of Consumer Cooperation and the economic role on the national market.
\end{abstract}

Keywords: Supply Chain; Corporate Social Responsibility; Social Responsibility; Socio-Economic Development; Global Markets; The Coop Italia Case

\section{Corporations and Socio-Economic Development}

The extraordinary economic and social development in the second half of the twentieth century has made the advantages of a stable and long lasting peace evident.

Economic, social and technological growth took place with positive effects on standards of living never achieved before in human history.

The evaluation of great globalization processes can thus be only positive- even though ineluctable - as Nobel Prize for peace, Nelson Mandela stated comparing it with the course of seasons.

However, this should not made us hide the existence of contextual limits and negative consequences. The abolishment of borders was accompanied by the reduction of barriers, which undoubtedly means more freedom but also less

* Coop Italia, President (info@coopitalia.coop.it) 
protection for consumers, citizens and people. Globalization then appeared with all its benefits, but also its imbalances.

It is necessary to acknowledge a mechanism of distortion, where a small part of the global population is able to purchase, while the largest part is bound to purchase less and less, and that is the reason for a worrying stall of global economy.

Water: $41 \%$ of global population live in areas where water is lacking and in 2002 seven million people died for scarce water availability; in 2025 the demand for water will increase by $56 \%$.

Energy resources: per capita oil consumption of citizens in the North of the world is 31 times bigger than in the South of the world; half a billion cars in the North of the world burn a fourth of the produced oil, generating the $80 \%$ of total carbon monoxide and the $51 \%$ of nitrogen oxide; energy consumptions use for the $92 \%$ non renewable sources.

$\square \underline{\text { Forests: }}$ over the last 30 years, 418 million hectares of forest were lost; deforestation caused a $30 \%$ increase of carbon dioxide.

In many countries located in the South of the world we see the spreading of a dangerous identification between 'the rich' - 'the bad' - 'the enemies' which has led to a situation of great unpredictability, instability and insecurity on the market. At the same time, we cannot ignore a worrying waste of global natural sources: it is indeed in those Countries whose population does not have the minimum means of subsistence where vital 'ecosystems' should be defended.

An objective weak point in this big globalization process is the traditional system of States: once we had the scheme 'one State-one market', today it is 'more Statesone market'. This necessarily implies the need of a 'global governance' that, up to today, international bodies have not managed to guarantee (ONU - FMI - WTO to mention a few) and that, with the utmost respect, but also being objective, cannot be determined by one only Country.

Against this background the role of companies emerges, as possibly vital and decisive. Companies, as subjects creating social wealth, are and will always be required to be able to produce innovation, developing quality and profitability with fair prices on the market. At the same time, it is and will be necessary for companies to be able to be integrated into the society, giving positive answers to the market as well as to the social and environmental context in which they act. Companies today are strong subjects, and they must help and support institutions for a sustainable, and thus long-term, economical and social development. Today, large-scale retailers, and industrial companies in general cannot ignore the impacts generated by their activity, whether direct or indirect. The 'new way of thinking' they can adopt is an internal change that must always respond to market and business logics, but that can and must interact with the other actors of society for the most complex processes. 


\section{Corporate Responsibility and Global Markets}

The European Commission underlines how corporate responsibility is not an additional element with respect to companies' fundamental activities, but rather linked to companies' management itself.

Recently the belief according to which corporate social and environmental responsibility correspond to 'the set of rules through which a company operates on the market, respecting the well-being of a wide group of stakeholders, including workers, business partners, the community and the environment, thus safeguarding long term business sustainability' has been spreading around.

Today, the urgency to adopt socially responsible management policies is due also to the growing importance of characteristics related to companies' reputation and to the trust relationship between the company and its main interlocutors, as regards the choices of both consumers -that, as we will see, prefer companies that follow such a behaviour- and trade partners, large-scale distribution, where the continuous assessment of the respect of human and social rights by their suppliers has become the normal practice.

Several partnership projects have in fact been started in Europe, both in France and Germany, among large scale retailers, to verify the respect of SA8000 standards by their suppliers, in particular those from developing Countries, believing in the need for everybody to assess risks and in the opportunity to maximize profits and reduce costs. A company does not have to distinguish itself for specific solidarity initiatives, but it should rather adopt a socially responsible global management of its activity. This implies a long and sometimes complex process, where the collaboration between the different market actors becomes a key element for success. There's been for some years, at a European level, the political conviction that corporate social responsibility is 'closely related to the concept of long-lasting development', by which the European Community wants to be inspired for its political and operational choices. (The Charter of Fundamental Rights of the European Union, 2000).

To this regard, the European Commission has in fact undertaken an initiative to promote specific incentive policies, convinced that it could mean a value-added in terms of competition for the European system.

$\square$ In 2001 it was the Commission itself that, with the publication of the Green Book on social responsibility, initiated a process of consultation and dialogue based on the assumption that 'social responsibility regards all the company's stakeholders'. In 2002 this issue was included among the Commission's priorities. Since then, a Multistakeholder Forum was set up to involve all interested parts in the definition before 2004 of a feasible Community policy for companies that could be effective in the management of globalization processes. The European Parliament will reserve its right to legislate on the compulsoriness of some requirements before that date. 
This is the international contest for the Social Commitment project of the Ministry of Welfare. The Italian Government judges this theme as worthy of interest, so that it has included it among the 5 top priorities for the semester of the Italian Presidency of the Community and it aims at closing this semester with the approval, at the European level, of this legislative approach.

Practically, the project involves: the introduction of a self-evaluation system for companies regarding social and environmental impacts as well as their coparticipation in the Public Welfare, against tax allowances and recognisability on the market.

It is evident that at this point, companies would no longer be the sole responsible for the definition of how and with respect to what variables to address their improvement process, not to benefit from the effect related to it.

\section{Consumers Expectations and Attitudes}

Italian consumers seem to be more and more attentive to this theme, showing a relevant growing awareness and criticism; as a matter of fact, from 1999 to 2002, consumers who consider social responsibility a key element have increased from 36 to $84 \%$.

Two elements in particular are to be taken into consideration if a company wants to get a competitive plus to retain present consumers and to attract and increase future ones' loyalty:

- complying with the law is for the company a minimum requirement, not an element to be rewarded;

- the idea that is being developed more and more is that those companies whose structure is of great potential control on global processes, should be the responsible for social balance.

These new Italian consumers are less and less satisfied with companies' commitment to social responsibility, on the one side because of their growing awareness, on the other because of the spreading of more specific information on companies' behaviour.

If consumers, when asking more to companies, are not willing to pay an extra charge, they are however more inclined to buy.

To this regard, we should remember that if rewarding can be difficult, boycotting becomes instead a common practice where the alternative to branded products is easily available: between 2001 and 2002, in Italy, boycotting grew by six percentage points.

Because the relationship based on trust is established between consumers and the brand, that has to fully account for product characteristics, since consumers expect the company to act in the respect of workers and the environment, both internally and as regards suppliers. 


\section{Social Responsibility and the Supply Chain. The Coop Italia Case}

\subsection{The Coop System in the Evolution of Retail Large-Scale in Europe and Italy}

Towards the end of the 90's, two trends already in progress in Europe imposed themselves strongly on Italian large-scale retail: concentration and internationalization.

Italian top five retailers' market share was of $62.7 \%$ in 2000 and of $89.4 \%$ in 2002 , thus indicating a $26.7 \%$ increase; at the same time, the market share of the Buying Centrals linked to international groups increased from $3.5 \%$ in 1995 to $49 \%$ in 2002.

In this context, Coop stands as a point of reference for Italy 'Country system', both for the historical role of service of Consumer Cooperation and the economic role on the national market.

Coop aims at safeguarding and improving a national retailing model to stem the risk of an indistinctive levelling based on foreign models, that are not always able to meet Italian culture, the needs of Italian consumers and of Italian economy and production.

In particular, Coop had excellent results in 2002 as regards: increased turnover $(7,4 \%)$; development (+ $90.000 \mathrm{sq} \mathrm{m})$; employees $(+2.950)$; members $(+293.300)$ and profitability. These results are not random, but rather the fruit of a long cycle established over the last twenty years.

The company worked with determination on business and sales network, achieving a progressive reduction in the number of Cooperatives and a significant modernization of store formats, in particular with the development of hypermarkets and the modernization of supermarkets. Notable investments in loyalty policies and in the relation with territory produced a strong increase of the number of members. The increased sales (at constant prices), which more than tripled from 1982 to 2002, went together with increased employment, in particular as regards stores, with huge investments in human resources training activities.

\subsection{Responsible and Qualified Development of Coop Italia 'Channels'}

In a national context where the growth of the 'modern' has not yet reached the level of the other major European countries, Coop carries on the process of development and modernization of its sales network, contributing to improve and consolidate the Italian model.

In order to contribute to the modernization of the Italian offer, Coop's development plan from 2002 to 2005 includes:

- the opening of 91 new stores, hypermarkets and supermarkets;

- over 10.000 new employees for the new structures;

- a new total area of sale of over $300.000 \mathrm{sq}$ m;

- a turnover increment of over $2.500 \mathrm{Mln} €$;

- an estimated increase of market share by over 4 percentage points.

All this with investments for around $2 \mathrm{~B} \ln €$. 
Large part of these investments will be realized in Central-Southern Italy.

The positive sales trend, produced by both the strong ties with members and territory, and the innovative boost, allowed Coop to maintain and consolidate its share leadership on the national market, also thanks to the centralization processes analyzed above. Such results are a tangible sign of customers appreciation of our offer policy. Safety and good value, in a difficult economic situation, are strong benchmarks, certainties much appreciated by our customers. These results come from reliability and trust: the main thing, in our opinion, that should be given to Italian and global economy.

Coop has decided to launch the social responsibility theme based on the idea that its essential motivations, that made Coop take action through the years to address these priority issues, could and should be shared today by manufacturers and suppliers.

Figure 1: From Quality to Ethics

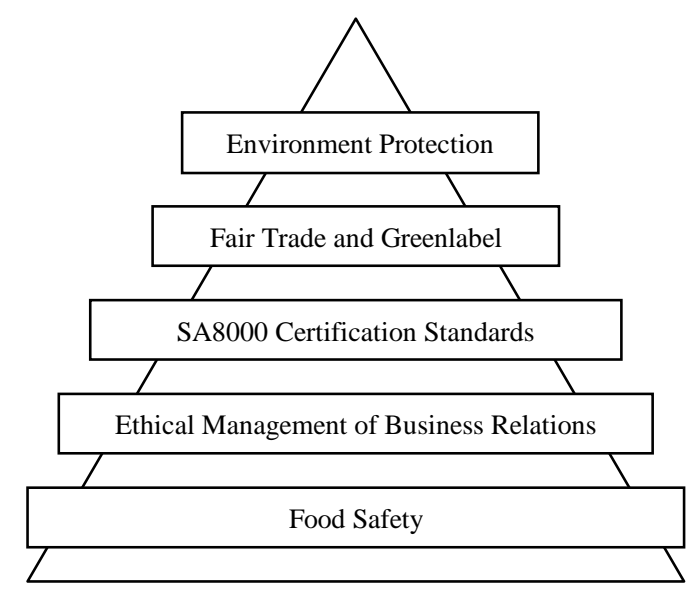

\section{Food Safety}

Over the last few years, we have seen the growing importance of activities for the control on food safety, against unscrupulous, non extensive production processes, that generated real dangers and justified worries for the health of consumers.

To this regard, Coop policy has been clear:

- to privilege the direct control throughout the production chain;

- to provide consumers only with safe products, preferring 'not to offer' rather than putting their safety at risk.

$\square$ We can take into consideration the typical case of meat safety management, that implied the following:

- elimination of all flours of animal origin, not only those coming from ruminant animals, from the feeding of animals that will become Coop PL meat;

- GMO-free feedstuffs;

- as for breeding, use of natural methods, respectful of the environment and the animals, and constant 
control on the production chain, thus allowing the traceability of 'Coop animals' and the compliance with safety standards for breeding, throughout the process from cattle to shelves.

The attention to safety involves all the products. In particular, potential suppliers for Coop Private label, are evaluated, according to products and production cycle, by means of a request for documentation and of audits at production or breeding sites, favouring national suppliers for fresh food products; the same suppliers are then followed through the supply process with audits and regular controls: sample controls on delivered products; direct controls at production or breeding sites; controls on shelves.

Coop Italia has its own laboratory which operates in those sectors where there is a strategic need for direct controls:

- molecular biology: to check the possible presence of GMOs;

- sensory evaluation of products: to test products characteristics related to agreeableness;

- microbiological tests: to check the products that are particularly critical from the microbiological point of view (fresh and ready to use products).

\section{Coop Commitment to Environment Protection}

The commitment to environment protection has always been part of Coop institutional strategy, it was pursued with determination in the context of the activity aiming at defending consumers' rights, and it generated a wide plan for the environment, that involves all the aspects of Coop distinctive activity: environmental education, training and advertising; Coop Private label products; stores, sites and logistics; packaging and waste management.

Coop carries out projects on consumers health and environment protection, considering on one side the need to safeguard resources available today for the development of tomorrow and on the other the tight link between people health and the environment they live in.

In particular, the activities related to Coop Private Label products involved: the use of integrated pest management and organic production, Ecolabel certification for categories of products with high environmental impact, adoption of specific standards for sustainable fishing.

In the past we always tried to meet the challenge for process and product innovations to guarantee the most sustainable product to members.

Participating to certification plans is one of the way through which Coop is trying to introduce to the logics of large-scale retail choices and management models that lead to a better global balance.

For a large-scale retailer, the ability to reduce packaging materials is a distinctive element in reducing emissions. To this regard, Coop has adopted the EuroCoop 'Chart of Commitments ' and it carried out through the years several actions both on the recycling of packaging produced and employed and on the reduction of packaging weight per each production unit. 
At the same time, the complex issue of reducing the impact of stores was taken into consideration, with the support and engagement of the whole Coop system.

Since the ' $80 \mathrm{~s}$, Coop has in fact adopted, thanks to the work of Inres (Istituto Nazionale Ricerca e Sviluppo), innovative criteria for the design of sale structures, as well as for the management of production facilities and equipments, in order to reduce the consumption of natural resources and produced emissions, concentrating on the adoption of new technologies.

Such actions not only improve the relation between Coop and the territory where it operates, but they also tend to produce in the course of time a significant cut in costs bound to resources.

Several producers worked on the same direction to manage the impact of their activities on the environment, anticipating in some cases the relevant legislative amendments.

\section{Management of Business Relations}

Guaranteeing safety is a necessary requirement, that has to be supported by ethical behaviours in the management of trade relations, both with consumers and between trade partners.

For Coop, this was translated into the will to guarantee 'honest' prices to defend the purchasing power of its members, and in particular to curb inflation. In 2002, Coop sale inflation (for food products) was significantly lower than the national trends, with 2,3 points below Istat Index(Coop 1,4\% vs Istat 3,7\%.)

On the occasion of the difficult switch from Lira to Euro, Coop succeeded in managing the significant rise in inflation, also thanks to transparent management and collaboration with suppliers.

The efficiency of Coop system is and will be growing, improving the already positive relation with the industry, where Coop suppliers were and still are reliable and collaborative partners.

\section{Fair and Solidal}

The great part of social and solidarity initiatives are closely linked to the territorial reality in which our Cooperatives operate, with the benefits of a social structure that is voluntary, articulate and rooted, and that has been creating value for years.

The social as well as sustainability CSR Reviews of Cooperatives have become already a result that is appreciated by everybody.

Coop carried on its commitment to developing countries with fair and solidal trade, based on the idea that it is necessary to get to the root of the problem, by means of making the communities that are today in difficult circumstances autonomous.

The aim of Fair Trade is to give a contribution to rebalance the relations with developing countries, promoting their access to market and improving life conditions of small producers. This can be achieved by means of a more equal distribution of profits, through an equal relation of all the subjects involved in the production chain: suppliers, workers, importers, distributors and consumers. 
This type of trade relation is based on reciprocal collaboration and respect between producers of the developing countries and consumers of the developed ones, and it promotes social justice, economic equity, sustainable development, respect for the people and the environment.

In 2002 Coop took a more direct and incisive responsibility on this issue, including fair trade products in its private label range, making this one of the strategic components of its offer, and designing a long term development plan to respond to a wide range of needs through several product categories.

\section{SA8000 Certification}

In order to try to balance the disproportions of the production system, Coop was the first European company to adopt, in 1998, the SA8000 Standard; this is the only international standard valid for all sectors, that can be certified by an external entity, and that regulates a correct ethical behaviour of companies and of the production chain towards workers, establishing a profitable relation between companies and civil society.

The fact that SA 8000 requirements are based on the respect of national and international legislation (ILO and ONU) gave us an authoritative and internationally recognized point of reference on what we could legitimately ask for, relying on the public acknowledgement of such regulations.

Furthermore, a gradual approach, inspired by a continuous improvement, has reassured us regarding the possible risks related to intervening in complex mechanisms with inappropriate logics, thus allowing us to manage trade relations from the point of view of reciprocal growth. In the first three years, certification was concentrated on Coop private label suppliers (around 300), with some outstanding successes, culminated with the assignment, in New York, of the Corporate Conscience Award

The logic that inspired the relation with suppliers was to analyze thoroughly the most critical supply chains, by means of contacting NGOs and trade unions, and organizing operative meetings with direct suppliers to jointly intervene throughout the supply chain.

\section{Coop Private Label and Corporate Responsibility}

Coop Private Label is practically born with Coop, and its mission towards consumer members. The aim is to guarantee, by a continuous innovation, a product that always keeps up with the changing times and needs. Thousands of analysis and tests are carried out every year, in Coop laboratories and at suppliers, so as to guarantee high quality standards; Coop is certified SA8000 and its suppliers have subscribed to a ethical code of conduct. All the products are GMO-free certified. The packaging is designed to reduce the impact on the environment to the minimum, and if possible is made with recyclable materials. The products are tested by panels of consumers, selected among members of the major Cooperatives. 
Moreover, high volumes of purchase guarantee a high quality-price ratio for consumers as a safeguard for them.

The mandatory requirements to be granted the Coop sign brand are the following:

- intrinsic quality: for example, Coop has chosen caution with respect to GMOs, so that Coop private label products are GMO-free certified;

- safety: control of the agroindustrial chain;

- ethics: products certified for ethical production methods;

- good value: the best products at the best price;

- $\quad$ respect for the environment: attention to packaging;

- perceived quality: approved by members (over 35000 members involved).

\subsection{The Perception of a Socially Responsible Behaviour}

Consumers brand awareness improves together with the company's growth. In 2002, Coop confirmed to be the first retailer in consumers' top of mind: with a 15 points gap from the second retailer, and a 3,5 points increase with respect to the preceding year.

Figure 2. Brand Awareness

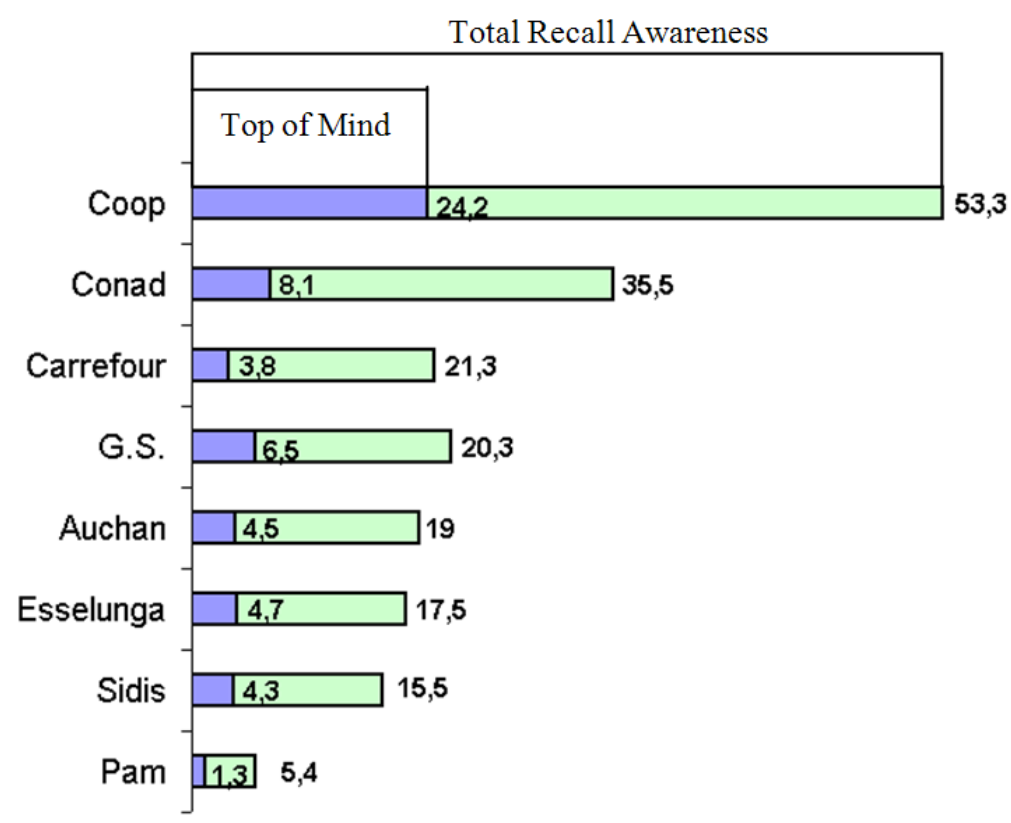

This has given a strong impulse to economic and trade results, with a significant growth of Coop customer satisfaction (around $+1 \%$ out of 25.000 interviews carried out at Coop super and hypermarkets) in a market situation that sees a general decrease of customer satisfaction with respect to past years.

Finally, Coop was judged, by a 2002 survey, among the first ten Italian companies with best reputation. In particular, as a proof of the efficiency of the policies promoted so far, Coop ranks first for social responsibility. 
COOP's figures and reputation show how the market positively welcomes business logics that pay attention to people and the environment, able to respond to consumers new needs, and that must be tested and promoted.

Figure 3. Customer Satisfaction Index 2002 and $\Delta$ vs 2001

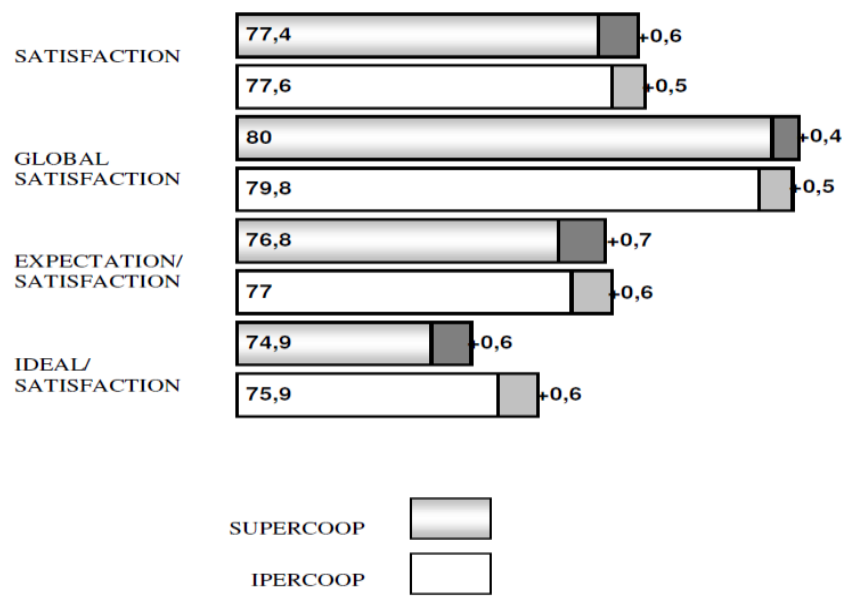

\section{Coop and the Industry: the Category Management as Effective/Ethical Answer to Consumers}

New consumers ask for products of a different value, that should go beyond the simple price-quality ratio, and expect that stores where they purchase can guarantee this. Some local Public Authorities as well (Regione Toscana, Regione Umbria, Province of Lecce) are working at the 'management' of this process, thus showing that it is possible to concur to the establishment of a virtuous mechanism able to: satisfy consumers; make companies competitively distinctive; exploiting the territory, by means of promoting socially responsible behaviour, that can be verified and thus credible and appreciated on the market.

Today it is then important to anticipate such phenomena by making retailers, key actors of trade relations, the promoters of a new way of business, and benefiting from this role of model-builders.

They are in fact offered the chance to operate not only for their direct benefit, but also and most of all for the requalification of 'Sistema Italia', that in this very moment of economic recession needs to improve distinctive, characteristic elements.

This high collaborative relation is based on the primary target of maximizing customer satisfaction and creating value for industry and retailers.

There is little doubt about the fact that partnership build up process is the core issue by which industry and distribution search for business opportunities that may satisfy both parts involved, providing the consumer with the right answer by keeping into consideration also the reputation and the role played by the distributor.

The demand for ethicality affects indirectly all customers: we have always been trying to do our best in order to build up a coherent system of values and products, particularly, as we have seen before, as far as our labelled products are concerned. 
Today there is room for a new frontier of marketing, that be respectful of the cultural and environmental contexts and that pay attention to the customer perceived as person as well as citizen.

It is not about accepting new constraints and requirements, but rather about working throughout the supply chain in order to safeguard the reputation, protecting consumers' values in the first place.

In brief, the entrepreneurial world is called to develop a virtuous pathway in order to bring at the core of our attention the concept of satisfaction of a new consumer, aware of the fact that their purchase is turning out to be a vote and that such a vote will not only have its effects on the company itself, but also on subjects who are far and not directly involved in the process and whose life styles are a source of moral, social and political concern.

Adam Smith, in 1776, in his masterpiece about economic liberalism entitled 'An Inquiry into the Nature and Causes of the Wealth of Nations' wrote: 'the economic subjects operating on the market act always for their own interest and the free mechanism of supply and demand keeps the market balance in favour of public interest'.

But from Adam Smith we have moved to Enron, to the food and environmental catastrophes. All that as a result of a 'greedy capitalism' as we can find in Alan Greenspan's words.

We do not intend to revolutionize the existing economic model.

But if we managed to reduce all elements related to 'market fundamentalism' in favour of a greater ethicality and social liability, we would certainly bring our contribution for a better growth of the world, of Italy and of our companies. 